\title{
Exigências Líquidas de Proteína e Energia para Crescimento de Tourinhos Santa Gertrudis em Dietas de Alto Teor de Concentrado ${ }^{1}$
}

\author{
Alexandre Berndt ${ }^{2}$, Wignez Henrique ${ }^{3}$, Paulo Roberto Leme ${ }^{4}$, Guilherme Fernando Alleoni ${ }^{5}$, \\ Dante Pazzanese Duarte Lanna ${ }^{6}$
}

\begin{abstract}
RESUMO - Foram utilizados 32 tourinhos Santa Gertrudis inicialmente com dez meses de idade e $245 \mathrm{~kg}$ de peso, alimentados em confinamento com dietas contendo $88 \%$ de concentrado. Quatro animais foram abatidos no início do experimento (linha base) para estimativa da composição corporal inicial. Os 28 animais restantes foram distribuídos em baias individuais com delineamento de blocos ao acaso em arranjo fatorial $2 \times 2$ (dois volumosos x dois processamentos do milho grão) com sete repetições. Os volumosos incluíam silagem da planta de milho ou bagaço de cana-de-açúcar e os dois processamentos do grão de milho, o grão colhido seco e triturado e o colhido e ensilado úmido. Estimou-se, por intermédio da regressão do logaritmo do conteúdo corporal de energia, em função do logaritmo do peso do corpo vazio, o conteúdo de energia e proteína para ganho de peso em qualquer faixa de peso vazio incluída neste trabalho: para ganho de $1 \mathrm{~kg}$, em um animal de $300 \mathrm{~kg}$, foram necessárias 3,64 Mcal/dia de energia e 129,5 g de proteína.
\end{abstract}

Palavras-chave: bagaço de cana, bovinos, confinamento, exigências, milho de alta umidade

\section{Net Protein and Energy Requirements for Growth of Santa Gertrudis Young Bulls Fed High Concentrate Diets}

\begin{abstract}
Thirty two Santa Gertrudis bulls with ten months of age and $245 \mathrm{~kg}$ average live weight were fed $88 \%$ concentrate diets with corn silage or sugarcane bagasse and dry corn or high moisture corn. Four animals were slaughtered in the beginning of the experiment for initial body composition determination. Other 28 animals were distributed on four treatments. The experimental design was randomized blocks in $2 \mathrm{X} 2$ factorial (two roughage $\mathrm{X}$ two corn sources) with seven replicates. Regression equation of log body energy content as a function of log empty body weight (EBW) provided estimation of body energy content at any EBW range included in this research: for weight gain of $1 \mathrm{~kg}$, an animal of $300 \mathrm{~kg}$ requires $3.64 \mathrm{Mcal} /$ day of energy and $129.5 \mathrm{~g}$ of protein.
\end{abstract}

Key Words: bulls, energy requirements, feedlot, sugarcane bagasse, high moisture corn

\section{Introdução}

A determinação das exigências de energia para mantença e crescimento de bovinos de corte é importante, pois a maior parte da energia bruta fornecida ao animal com o objetivo de produzir carne é utilizada em função de mantença: manutenção dos gradientes das membranas, síntese de macromoléculas, manutenção da homotermia, movimentação e atividade física (NRC, 1996).

Novilhos desmamados recebendo alimentos de baixa qualidade e ganhando $250 \mathrm{~g} / \mathrm{dia}$ retêm apenas $3 \%$ da energia destes alimentos; $46 \%$ são perdidos nas fezes e $41 \%$, como calor. Um tourinho em confinamento crescendo rapidamente e recebendo uma dieta altamente digestível retém $37 \%$ da energia presente nos alimentos, dissipando 55\% como calor (Webster, 1989). Signoretti et al. (1999b), comparando o desempenho de tourinhos recebendo diferentes níveis de volumoso, observaram que a eficiência de utilização da energia metabolizável para ganho de peso foi maior para dietas com menor nível de volumoso, isto é, maior nível de energia bruta na dieta, obtendo valores de eficiência da ordem de $40 \%$. Ferreira et al. (1998b), trabalhando com tourinhos cruzados Simental X Nelore, obtiveram valores médios de 27 a $42 \%$ de eficiência para rações com diferentes proporções de concentrado:volumoso. Estes exemplos demonstram que a utilização de energia pelos ruminantes mesmo com o uso de técnicas

\footnotetext{
${ }^{1}$ Projeto financiado pela FAPESP

2 Bolsista FAPESP, Pós-graduando ESALQ-USP/Piracicaba, Lab. de Nutrição e Crescimento Animal. Av. Pádua Dias nº 11, C.P. - 09, CEP 13418-900. E.mail: alberndt@esalq.usp.br

${ }^{3}$ Pesquisador Científico do IZ/São José do Rio Preto, Bolsista CNPq. E.mail: wignez@terra.com.br

4 Professor da FZEA/USP/ Pirassununga. E.mail: prleme@usp.br

5 Pesquisador Científico do IZ/Nova Odessa. E.mail: alleoni@izsp.br

6 Professor da ESALQ/USP/Piracicaba, bolsista do CNPq. E.mail: dplanna@esalq.usp.br
} 
avançadas é um processo ineficiente, quando comparado a outras espécies. Entretanto, deve-se considerar o fato de que outras espécies não são eficientes na transformação de resíduos fibrosos.

Diversos fatores alteram a eficiência de crescimento de bovinos, saber: peso, idade, nutrição, genética (raça e tamanho corporal), sexo, utilização de hormônios exógenos e manipulação do genoma (Lanna, 1997). A eficiência de crescimento de animais de corte é dependente, principalmente, de duas características básicas: taxa de ganho e composição química dos tecidos depositados. Quanto maior a taxa de ganho, maior a eficiência de conversão em função da diluição das exigências de mantença. As exigências de mantença podem variar em função do peso, raça, sexo, idade, estação do ano, temperatura, estado fisiológico e nutrição prévia (NRC, 1996). A determinação das exigências de mantença para raças cruzadas Bos taurus x Bos indicus é necessária para o desenvolvimento de modelos matemáticos de simulação do processo de digestão e metabolização de nutrientes. O Santa Gertrudis é composto por aproximadamente 5/8 Shorthorn e 3/8 Brahman. Existe controvérsia na utilização de valores tabelados para exigências de mantença determinados para raças puras em cruzamentos de Bos indicus com Bos taurus, pois alguns autores propõem que os requerimentos de mestiços seriam intermediários (Fox et al., 1992; , Lanna et al., 19956, 199792; Lana et al., 1992).

A composição química dos tecidos depositados é o segundo fator determinante da eficiência de crescimento. Quanto maior a proporção de tecido adiposo no ganho, maior a eficiência energética de deposição dos tecidos e menor a eficiência de conversão alimentar, pois a gordura é mais densa energeticamente.

As exigências de energia podem ser arbitrariamente divididas em exigência líquida para mantença (ELm) e exigência líquida para ganho (ELg) (Lofgreen \& Garret, 1968). As exigências de energia líquida para mantença equivalem à produção de calor pelo animal com ingestão de energia suficiente apenas para manutenção de um balanço energético neutro. Equivalem também à quantidade de energia metabolizável consumida na situação descrita acima. Estas exigências podem ser definidas como a quantidade de energia ingerida, que resulta em nenhuma perda ou ganho de energia no animal.

Por outro lado, as exigências de energia para ganho são estimadas pela quantidade de energia depositada como lipídios ou como matéria orgânica não lipídica,gordurosa (a maior parte proteína) e gordurosa que contém energia apenas na forma de proteína, uma vez que a fração de carboidratos é desconsiderada (NRC, 1984). A composição do ganho depositado é alterada, entre outros, pelo tipo genético, pela taxa de ganho e pelo teor e consumo de energia da dieta. Diversos autores (Araújo et al., 1998, a,b; Boin, 1995; Lanna, 1998; Ferreira et al., 1998 a,b; Paulino et al., 1999 a,b; Signoretti et al., 1999b,c), em experimentos realizados no Brasil, têm procurado determinar as exigências nutricionais de energia para crescimento, por intermédio de regressões do logaritmo do conteúdo corporal de energia, em função do logaritmo do peso do corpo vazio.

As exigências de energia para diferentes taxas de ganho não são linearmente correlacionadas. Ganho elevado de peso implica em maior teor de energia no ganho. Geay (1984) afirma que o conteúdo de gordura no ganho de peso é influenciado por fatores como raça, sexo, peso corporal e taxa de ganho. Boin (1995) observou para o Nelore aumento no teor de energia do ganho, em função da taxa de ganho; o mesmo foi demonstrado por Lanna et al. (1998) com mestiços zebuínos.

Oltjen \& Garret (1980) relataram que a proporção de energia, proteína e gordura no ganho de peso vivo varia mais em função do peso corporal do que da taxa de ganho. Entretanto, o uso de procedimentos e equações que utilizam o GVP como parâmetro (NRC, AFRC, RLM) aumenta a precisão das estimativas da composição do ganho, permitindo melhor estimar as exigências nutricionais de energia para crescimento.

Brody (1945) mostrou uma relação curvilínea entre energia retida e energia bruta consumida para ruminantes em crescimento ou engorda. Constante incremento no consumo de energia diária resulta em aumentos decrescentes na retenção de energia por dia. Segundo Reid et al. (1955), esta redução ocorreria pela depressão na digestibilidade da dieta, quando o nível de consumo aumenta. Esta redução seria determinada pela aceleração da taxa de passagem. Não obstante, embora os trabalhos de Garrett para elaboração do NRC não tenham sido corrigidos para depressão da digestibilidade, pesquisas subseqüentes demonstraram que, efetivamente, esta relação é curvilínea e com eficiência decrescente. Esta curvilinearidade deve estar ligada a um aumento de processos como turnover de macromoléculas e para manutenção dos potenciais de membrana no animal.

\section{R. Bras. Zootec., v.31, n.5, p.2098-2104, 2002}


Este trabalho foi conduzido com o objetivo de fornecer dados que possam ser utilizados poderão ser utilizados como parâmetros em programas de estimativa das exigências nutricionais e programas de simulação do desempenho (NRC, 1996; RLM 2.0).

\section{Material e Métodos}

Foram confinados 32 tourinhos Santa Gertrudis, com idade média de 10 meses e peso inicial médio de $245 \mathrm{~kg}$. Os animais foram mantidos em baias individuais, parcialmente cobertas, por 124 dias (período experimental), após adaptação de 33 dias. O delineamento utilizado foi de blocos ao acaso em arranjo fatorial 2x2 (dois volumosos $\mathrm{x}$ dois processamentos do milho grão) com sete repetições, testados os seguintes tratamentos: silagem de milho + milho úmido (Si-MU); silagem de milho + milho seco (Si-MS); bagaço cru + milho úmido (Ba-MU); e bagaço cru + milho seco (Ba-MS).

A composição detalhada da dieta está descrita em Berndt et al. (2002).

O milho úmido foi colhido quando o grão apresentava 30\% de umidade e, após moagem, foi ensilado em silo trincheira. O milho grão foi colhido e seco até $13 \%$ de umidade. As dietas foram balanceadas segundo o modelo CNCPS -Cornell Net Carbohydrate and Protein System (Fox et al., 1992), sendo que os tratamentos com silagem de milho apresentavam uma relação volumoso:concentrado de 20:80 e os tratamentos com bagaço de cana-de-açúcar, de 12:88, uma vez que a silagem de milho continha $40 \%$ de grãos.

A dieta completa foi fornecida duas vezes ao dia, sendo a composição corrigida semanalmente em função da matéria seca. Os animais foram pesados no início, após períodos de 28 dias e no final do período experimental após jejum de 18 horas.

Para este estudo de uso de energia utilizou-se a técnica de abates comparativos. Em contraste à calorimetria, em que a ingestão de energia metabolizável e a produção de calor são diretamente determinadas; a energia retida é estimada por abates comparativos; e a energia retida é medida de forma direta (Ferrell, 1988).

Quatro animais (linha base) foram abatidos para cálculo da composição corporal inicial. Quinze animais foram abatidos após 110 dias e 13, após 124 dias, de forma a apresentar acabamento semelhante, para facilitar a retirada do corte da $9-11^{\mathrm{a}}$ costelas (seção HH), conforme Hankins \& Howe (1946), utilizando equações de regressão desenvolvidas para animais desta categoria e raça (Henrique et al., 2002).

A composição do corte das costelas (seção $\mathrm{HH}$ ) fornece equações de regressão para estimativas da composição da carcaça melhores que outros métodos (Lanna, 1988).

Para estimar a porcentagem de água e gordura no peso do corpo vazio, a partir da porcentagem de extrato etéreo na $9-11^{\text {a }}$ costelas, utilizaram-se as seguintes equações desenvolvidas para a raça (Henrique et al., 2002):

Equação 1: \% água $\mathrm{PVz}=1,0559$ \% água - 1,9804 $\left(r^{2}=0,92\right)$

Equação 2: \% gordura $\mathrm{PVz}=-1,1411 \%$ água $+83,023$ $\left(r^{2}=0,91\right)$

Regressões lineares entre peso vazio inicial e peso vivo em jejum inicial da linha base foram determinadas para fornecer melhor estimativa do peso vazio inicial dos 28 animais que entraram no confinamento e foram abatidos posteriormente.

Os valores de energia dos ingredientes da ração, ou seja, a energia ingerida, foram determinados a partir de análises bromatológicas e equações de Kearl (1982). As quantidades de energia no corpo vazio e ganho de peso vazio foram determinadas a partir da composição corporal dos animais (Berndt et al., 2002), taxas de deposição dos constituintes químicos corporais e respectivos equivalentes calóricos segundo a equação (ARC, 1980):

$$
\mathrm{E}(\mathrm{Mcal})=5,6405 \mathrm{X}+9,3929 \mathrm{Y}
$$

em que $\mathrm{E}$ refere-se à energia (Mcal); $\mathrm{X}$, à proteína corporal $(\mathrm{kg})$; e Y, à gordura corporal $(\mathrm{kg})$.

As exigência de energia líquida para mantença (Elm) foram determinadas pela regressão do logaritmo da produção de calor, em função do consumo de energia metabolizável (EM), em kcal por unidade de peso metabólico, extrapolando-se a equação para zero de consumo de EM (Lofgreen \& Garrett, 1968). Também foram ajustadas equações de regressão do conteúdo corporal de energia, em função do peso corporal vazio, possibilitando estimar as exigências de energia e proteína para ganho de peso em determinadas faixas de peso vivo.

\section{Resultados e Discussão}

Apesar deste experimento não ter sido delineado para determinação exata das exigências de energia para mantença, são apresentados os resultados da regressão ressaltando que estes não podem ser com-

R. Bras. Zootec., v.31, n.5, p.2098-2104, 2002 
parados à maioria dos dados de literatura, em função de não se ter um grupo de animais mantidos próximos à mantença.

Obteve-se a equação $\log \mathrm{PC}=1,914927+$ 0,001334.IEM por intermédio da regressão do logaritmo da produção de calor, em função da ingestão de energia metabolizável, em kcal/ kg PVz ${ }^{0,75}$.d. A partir desta equação, com consumo de energia metabolizável igual a zero, determinou-se a exigência de energia de mantença para tourinhos da raça Santa Gertrudis em $82,2 \mathrm{kcal} / \mathrm{kg} \mathrm{PVz}^{0,75}$.d. O valor muito baixo do coeficiente de determinação é função da utilização de dados individuais de relativamente poucos animais, em contraste com Lofgreen \& Garrett (1968), que utilizaram dados médios de baias com seis animais, trabalhando com mais de 300 animais. A energia retida em função do ganho de peso vazio foi muito variável possivelmente devido à variação entre os animais. Animais de mesmo peso com ganhos semelhantes apresentaram diferenças na composição do ganho, indicando que alguns animais apresentaram elevado potencial de crescimento muscular, enquanto outros depositaram gordura mais precocemente.

As exigências líquidas de energia para ganho de peso foram determinadas a partir da equação de regressão do logaritmo do conteúdo corporal de energia, em função do logaritmo do peso do corpo vazio:

Log Energia = 0,7425 log PVz 1,4691

Analogamente, as exigências de proteína para ganho de peso foram determinadas a partir da equação de regressão do logaritmo do conteúdo corporal de proteína em função do logaritmo do peso do corpo vazio:

Log Proteína= 1,2313 log PVz 0,671.

As estimativas de exigências líquidas de energia e proteína para ganho de $1 \mathrm{~kg}$ de $\mathrm{PVz}$ em diferentes faixas de peso vazio estão na Tabela 1 e são também apresentadas na forma gráfica na Figura 1.

Como neste trabalho o ganho de peso médio dos animais nos tratamentos foi de $1,270 \mathrm{~kg} / \mathrm{dia}$, seria mais correto expressar as exigências de energia e proteína para esta faixa de ganho de peso (Tabela 2).

As exigências de energia para diferentes taxas de ganho não são linearmente correlacionadas. Ganho elevado de peso implica em maior teor de energia no ganho. Geay (1984) afirma que o conteúdo de gordura no ganho de peso é influenciado por fatores como raça, sexo, peso corporal e taxa de ganho.

A regressão entre a energia retida $\left(\mathrm{kcal} / \mathrm{kg}^{0,75} . \mathrm{d}\right)$ e o ganho de peso $(\mathrm{kg} / \mathrm{d})$ não é linear, indicando que a composição do ganho muda, à medida que a taxa de
Tabela 1 - Exigências líquidas de energia (Mcal) e proteína (g) para ganhos de $1 \mathrm{~kg}$ de peso vazio Table 1 - Net energy (Mcal) and protein $(\mathrm{g})$ for $1 \mathrm{~kg}$ of empty body weight gain

\begin{tabular}{lccc}
\hline $\begin{array}{l}\mathrm{PVz}(\mathrm{kg}) \\
E B W(\mathrm{~kg})\end{array}$ & $\begin{array}{c}\mathrm{GPVz}(\mathrm{kg}) \\
\text { EBWG }(\mathrm{kg})\end{array}$ & $\begin{array}{c}\text { Energia }(\mathrm{Mcal}) \\
\text { Energy }(\text { Mcal })\end{array}$ & $\begin{array}{c}\text { Proteína }(\mathrm{g}) \\
\text { Protein }(\mathrm{g})\end{array}$ \\
\hline 300 & 1 & 3,64 & 129,5 \\
350 & 1 & 4,09 & 123,1 \\
400 & 1 & 4,54 & 117,8 \\
450 & 1 & 4,98 & 113,4 \\
500 & 1 & 5,42 & 109,5 \\
\hline
\end{tabular}

ganho se altera (Figura 2).

Nesta regressão foram utilizados dados de dois experimentos utilizando tourinhos da raça Santa Gertrudis alimentados com dietas de alta energia (Berndt et al., 2002; Leme et al., 2000). Foram determinadas duas equações, diferindo apenas na interseção da reta com o eixo Y no ponto zero, que representa acúmulo zero de energia com nenhum ganho de peso.
Equação 1: ER $\left(\mathrm{kcal} / \mathrm{d} \cdot \mathrm{kg}^{0,75}\right)=28,094 \mathrm{GPVZ}^{2}$ $(\mathrm{kg} / \mathrm{d})+21,216 \mathrm{GPVz}(\mathrm{kg} / \mathrm{d})+6,0383$ $\mathrm{r}^{2}=0,80$;

Equação 2: ER $\left(\mathrm{kcal} / \mathrm{d} \cdot \mathrm{kg}^{0,75}\right)=22,41 \mathrm{GPVZ}^{2}$ $(\mathrm{kg} / \mathrm{d})+33,538 \mathrm{GPVz}(\mathrm{kg} / \mathrm{d}) \mathrm{r}^{2}=0,79$.

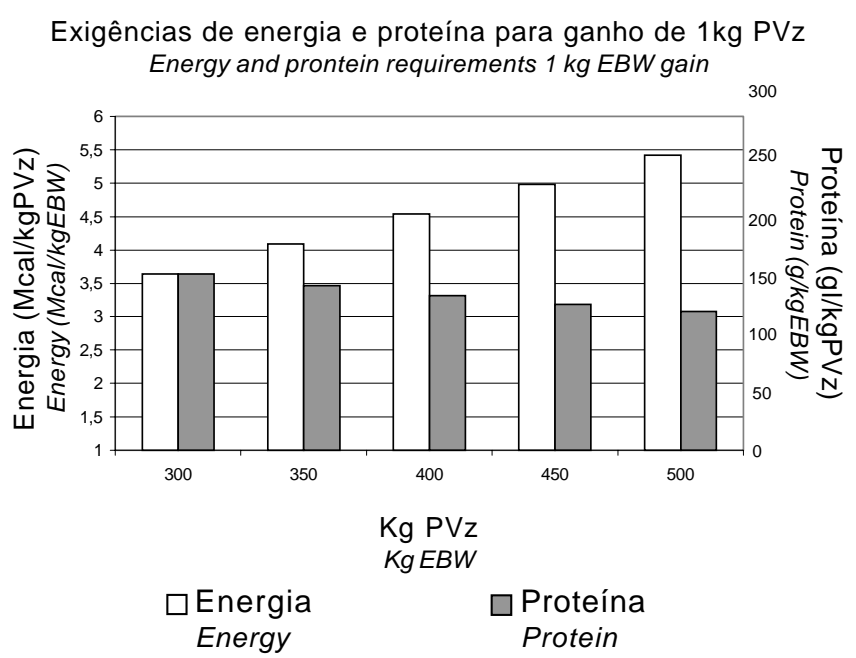

Figura 1 - Exigências de Energia (Mcal/kgPVz) e Proteína $(\mathrm{g} / \mathrm{kgPVz}$ ) para ganho de $1 \mathrm{~kg}$ de Peso $\operatorname{Vazio}(\mathrm{kg} / \mathrm{d})$.

Figure 1 - Energy (Mcal/.kgPVz) and protein ( $/ \mathrm{kg} E B W$ ) for 1 $\mathrm{kg}$ of empty body weigth weight gain $(\mathrm{kg} / \mathrm{d})$. 
Tabela 2 - Exigências líquidas de energia (Mcal) e proteína (g) para ganhos de 1,270 kg de peso vazio

Table 2 - Net energy (Mcal) and protein (g) for $1.270 \mathrm{~kg}$ of empty body weight gain

\begin{tabular}{lccc}
\hline $\mathrm{PVz}(\mathrm{kg})$ & $\begin{array}{c}\text { GPVz }(\mathrm{kg}) \\
E B W(\mathrm{~kg})\end{array}$ & $\begin{array}{c}\text { Energia }(\text { Mcal }) \\
\text { Energy }(\text { Mcal })\end{array}$ & $\begin{array}{c}\text { Proteína }(\mathrm{kg}) \\
\text { Protein }(\mathrm{g})\end{array}$ \\
\hline 300 & 1,270 & 4,62 & 164,5 \\
350 & 1,270 & 5,19 & 156,3 \\
400 & 1,270 & 5,79 & 149,6 \\
450 & 1,270 & 6,33 & 144,0 \\
500 & 1,270 & 6,89 & 139,1 \\
\hline
\end{tabular}

Brody (1945) mostrou uma relação curvilínea entre energia retida e energia bruta consumida para ruminantes em crescimento ou engorda. Constante incremento no consumo de energia diária pode resultar em pequenos progressivos aumentos na retenção de energia por dia, porque a energia da dieta decresce quando o nível de consumo aumenta, principalmente pela aceleração da taxa de passagem (Araújo et al., 1998b).

Excesso de concentrado pode diminuir o consumo ou aumentar a possibilidade de distúrbios como acidose, reduzir a digestão do amido e dos carboidratos da parede celular, diminuindo a digestibilidade da ração como um todo e aumentando as perdas nas fezes (Geay, 1984).

$\mathrm{O}$ valor de exigência de energia para mantença obtido (82,2 kcal/ $/ \mathrm{kg} \mathrm{PVz}^{0,75}$.d) foi elevado (7\% acima do previsto no NRC, 1996), mas consistente com as condições do experimento: animais taurinos, inteiros, alimentados com dietas ricas em energia que iniciaram o confinamento após longo período de suplementação com "creeper" e no próprio confinamento.

Segundo Ferrell et al. (1976), o tamanho dos órgãos internos (maiores em taurinos que em zebuínos) pode explicar, em parte, as variações nas exigências de energia líquida para mantença entre diferentes grupos genéticos. Da mesma forma, Smith \& Baldwin (1974) sugeriram que as diferenças no tamanho relativo dos órgãos poderiam estar associadas às diferenças nas exigências de mantença, demonstrando que fígado, coração, glândulas mamarias e tecidos do trato gastrintestinal estão entre os órgãos de maior atividade metabólica nos animais.

Ferreira et al. (2000) determinaram que os pesos do baço, fígado, rins, abomaso, intestino delgado, intestino grosso e gordura interna aumentaram e o conteúdo do trato gastrintestinal e o peso do omaso diminuíram linearmente com a inclusão de níveis crescentes de concentrado na dieta. Estes resultados foram muito semelhantes aos obtidos por Signoretti et al. (1999a).

Jorge et al. (1999) notaram redução de cerca de $20 \%$ nos pesos de fígado e componentes do trato gastrintestinal em zebuínos alimentados de forma restrita, quando comparados a animais em regime $a d$ libitum.

Araújo et al. (1998a) encontraram valores de $81,3 \mathrm{kcal} / \mathrm{kg}^{0,75}$.d para exigência de energia líquida para mantença; 3,46 Mcal de energia; e $196 \mathrm{~g}$ de proteína no quilo de ganho de peso vazio para tourinhos mestiços Holandês x Zebu de $300 \mathrm{~kg}$. Em animais de mesma categoria e peso de raça pura Holandesa, Signoretti et al. (1999b) obtiveram $110,46 \mathrm{kcal} / \mathrm{kg}^{0,75} . \mathrm{d}$ para exigências de mantença, 2,83 Mcal de energia e $183,2 \mathrm{~g}$ de proteína para ganho de peso.

Tourinhos cruzados Simental x Nelore com $350 \mathrm{~kg}$ de peso vazio necessitam de 3,02 Mcal/dia para depositarem $1 \mathrm{~kg}$ de peso (Ferreira et al., 1998a). Paulino et al. (1999a,b) encontraram valores de $60,4 \mathrm{kcal} / \mathrm{kg}^{0,75}$.d para exigência de energia líquida para mantença; 4,34 Mcal de energia; e 134 g de proteína no quilo de ganho de peso vazio para zebuínos de $400 \mathrm{~kg}$.



Figura 2 - Energia retida (kcal/d.kgPV0,75) em função da taxa de ganho de peso vazio $(\mathrm{kg} / \mathrm{d})$. Caixas incluem as equações de regressão, forçando-as pela origem ou não.

Figure 2 - Retained energy (kcal/d.kgPV0.75) as a function of empty body weighth gain $(\mathrm{kg} / \mathrm{d})$. Boxes show regression equations forcing through the origin or not. 


\section{Conclusões}

Os valores de exigências líquidas de energia para ganho de peso observados neste trabalho foram equivalentes aos propostos pelo NRC (1996) para animais de tamanho corporal semelhante. Estes resultados são consistentes com dados publicados pelo nosso grupo (Henrique et al., 1998; Lanna et al., 1988; Leme et al., 2000), bem como com trabalhos de outro grupo com a mesma raça (Backes et al., 1999).

A taxa de ganho altera a composição do ganho de peso e, portanto, modelos lineares entre ganho e exigências tendem a subestimar o teor de energia líquida em altas taxas de ganho.

\section{Literatura Citada}

AGRICULTURAL RESEARCH COUNCIL - ARC. The nutrient requirements of ruminant livestock: Commonwealth Agricultural Bureaux, 1980.351p.

ARAÚJO, G.G.L.; COELHO DA SILVA, J.F.; VALADARES FILHO, S.C. et al. Composição corporal e exigências líquidas de energia e proteína de bezerros alimentados com dietas contendo diferentes níveis de volumoso. Revista Brasileira de Zootecnia, v.27, n.5, p.1013-1022, 1998a.

ARAÚJO, G.G.L.; COELHO DA SILVA, J.F.; VALADARES FILHO, S.C. et al. Eficiência de utilização da energia metabolizável, para mantença e ganho de peso e exigências de energia metabolizável e nutrientes digestíveis totais de bezerros alimentados com dietas contendo diferentes níveis de volumoso. Revista Brasileira de Zootecnia, v.27, n.5, p.1031-1036, 1998b.

BACKES, A.A.; SANCHES, L.M.B.; PIRES,C.C. et al. Exigências de energia e proteína para ganho de peso de novilhos Santa Gertrudis. In: REUNIÃO ANUAL DA SOCIEDADE BRASILEIRA DE ZOOTECNIA, 36., Porto Alegre, 1999. Anais... Porto Alegre: Sociedade Brasileira de Zootecnia, 1999. CD ROM

BERNDT, A.; HENRIQUE, W.; LANNA, D.P.D. et al. Milho úmido, bagaço de cana e silagem de milho em dietas de alto teor de concentrado 2. Composição corporal e taxas de deposição dos tecidos. Revista Brasileira de Zootecnia, v.31, n.5, p.2105-2112, 2002.

BOIN, C. Alguns dados sobre exigências de energia e de proteína de zebuínos. In: SIMPÓSIO INTERNACIONAL SOBRE EXIGÊNCIAS NUTRICIONAIS DE RUMINANTES, 1995, Viçosa, MG. Anais... Viçosa, MG: Universidade Federal de Viçosa, 1995. p.457-465.

BRODY, S. Bioenergetics and growth. New York: Reinhold Publishing Corporation, 1945. 1023p.

FERREIRA, M.A.; VALADARES FILHO, S.C.; COELHO DA SILVA, J.F. et al. Composição corporal e exigências líquidas de proteína e energia para ganho de peso de bovinos $\mathrm{F}_{1}$ Simental X Nelore Revista Brasileira de Zootecnia, v.28, n.2, p.352-360, 1998a.

FERREIRA, M.A.; VALADARES FILHO, S.C.; COELHO DA SILVA, J.F. et al. Eficiência de utilização da energia metabolizável para ganho de peso e exigências de energia metabolizável e nutrientes digestíveis totais de bovinos $\mathrm{F}_{1}$
Simental X Nelore. Revista Brasileira de Zootecnia., v.28, n.2, p.368-373, 1998b.

FERREIRA, M.A.; VALADARES FILHO, S.C.; MUNIZ, E.B. et al. Características das carcaças, biometria do trato gastrintestinal, tamanho dos órgãos internos e conteúdo gastrintestinal de bovinos F1 Simental X Nelore alimentados com dietas contendo vários níveis de concentrado. Revista Brasileira de Zootecnia, v.29, n.4, p.1174-1182, 2000.

FERRELL, C.L.; GARRET, W.N.; HINMAN, N. et al. Energy utilization by pregnant heifers. Journal of Animal Science, v.42, n.4, p. 937-950, 1976.

FERRELL, C.L. Energy metabolism. In: CHURCH D.C. (Ed.) The ruminant animal, digestive physiology and nutrition. Illinois: Waveland Press, 1988. p.250-268.

FOX, D.G., SNIFFEN, C.J., O'CONNOR, J.D. et al. A net carbohydrate and protein system for evaluating cattle diets: III. Cattle requirements and diet adequacy. Journal of Animal Science, v.70, p.3578-3596, 1992.

GEAY, Y. Energy and protein utilization in growing cattle. Journal of Animal Science, v.58, n.3, p.766-778, 1984.

HANKINS, O.G.; HOWE, P.E. Estimation of the composition of beef carcasses and cuts. Washington, D.C.: USDA, 1946. 21p. (Technical Bulletin, USDA n.926)

HENRIQUE, W.; LEME, P.R.; LANNA, D.P.D. et al. Substituição de amido por pectina em dietas com diferentes níveis de concentrado. 1. Desempenho animal e características da carcaça. Revista Brasileira de Zootecnia, v.27, n.6, p.1206-1211, 1998.

HENRIQUE, W.; SAMPAIO, A.A.M.; LEME, P.R. et al. Estimativa da composição corporal de tourinhos Santa Gertrudis a partir da composição química e física das $9-10-11^{\mathrm{a}}$ costelas. Revista Brasileira de Zootecnia, 2002 (em tramitação)

JORGE, A.M.; FONTES, C.C.C.; PAULINO, M.F. et al. Tamanho relativo dos órgãos internos de zebuínos sob alimentação restrita e ad libitum. Revista Brasileira de Zootecnia, v.28, n.2, p.374-380, 1995.

KEARL, L.C. Nutrient requirements of ruminants in developing countries. Lugan: International Feedstuffs Institute, Utah Agricultural Experiment Station, Utah State University, 1982. p.271.

LANA, R.P.; FONTES, C.A.A.; PERON, A.J. et al. Composição corporal e do ganho de peso e exigências de energia, proteína e macroelementos minerais ( $\mathrm{Ca}, \mathrm{P}, \mathrm{Na}$ e $\mathrm{K}$ ) de novilhos de cinco grupos raciais. I. Conteúdo corporal e do ganho de peso em gordura, proteína e energia. Revista Brasileira de Zootecnia, v.21, n.3, p.518-527, 1992.

LANNA, D.P.D. Estimativa da composição química do corpo vazio de tourinhos Nelore através da gravidade específica da carcaça e da composição de cortes das costelas. Piracicaba: Escola Superior de Agricultura "Luiz de Queiroz", 1988. 131p. Dissertação (Mestrado em Agronomia) - Escola Superior de Agricultura "Luiz de Queiroz", 1988.

LANNA, D.P.D. Fatores condicionantes e predisponentes da puberdade e da idade de abate. In: SIMPÓSIO SOBRE PECUÁRIA DE CORTE, 4., 1997, Piracicaba. Anais... Piracicaba: Escola Superior de Agricultura "Luiz de Queiroz", 1997. p.41-78.

LANNA, D.P.D.; BOIN C.; ALLEONI G.F. ET AL. Estimativa da composição química corporal de tourinhos nelore através da gravidade específica. Revista Brasileira de Zootecnia, v.24, n.3, p.351-362, 1995.

LEME, P.R.; LANNA, D.P.D.; HENRIQUE, W. et al. Substituição do grão de milho por polpa de citrus em dietas com

R. Bras. Zootec., v.31, n.5, p.2098-2104, 2002 
diferentes níveis de concentrado. 2. Taxas de deposição e composição química corporal. Revista Brasileira de Zootecnia, v.29, n.3, p.834-839, 2000.

LOFGREEN,G.P.; GARRETT, W.N. A system for expressing energy requirements and feed values for growing and finishing beef cattle. Journal of Animal Science, v.27, n.3, p.793 806, 1988.

NATIONAL RESEARCH COUNCIL - NRC. Nutrient requirement of beef cattle. 6.ed. Washington, D.C.: 1984.90p.

NATIONAL RESEARCHCOUNCIL-NRC. Nutrient requirement of beef cattle. 7.ed. Washington, D.C.: 1996. 242p.

OLTJEN, J.W., GARRETT,W.N. Effects of body weight, frame size and rate of gain on the composition of gain of beef steers. Journal of Animal Science, v.66, p.1732. 1980.

PAULINO, M.F.; FONTES, C.A.A.; JORGE, A.M. et al. Composição corporal e exigências de energia e proteína para ganho de peso de bovinos de quatro raças zebuínas. Revista Brasileira de Zootecnia, v.28, n.3, p.627-633. 1999a.

PAULINO, M.F.; FONTES, C.A.A.; JORGE, A.M. et al. Exigências de energia para mantença de bovinos zebuínos não castrados em confinamento. Revista Brasileira de Zootecnia, v.28, n.3, p.621-626, 1999b.

RLM 2.0 - Ração de Lucro Máximo. Versão 2.0. LANNA, D.P.D., BARIONI, L.G.; BOIN, C.; TEDESCHI, L.O. Software de Formulação de Rações para Bovinos. Piracicaba: Escola Superior de Agricultura "Luiz de Queiroz", 1999.
SIGNORETTI, R.D.; ARAÚJO, G.G.L.; COELHO DA SILVA, J.F. et al. Características quantitativas das partes do corpo não integrantes da carcaça animal e desenvolvimento do trato gastrintestinal de bezerros da raça holandesa alimentados com dietas contendo quatro níveis de concentrado. Revista Brasileira de Zootecnia, v.28, n.4, p.875-882, 1999a.

SIGNORETTI, R.D.; COELHO DA SILVA, J.F.; VALADARES FILHO, S.C. et al. Composição corporal e exigências líquidas de energia e proteína de bezerros da raça holandesa alimentados com dietas contendo diferentes níveis de volumoso. Revista Brasileira de Zootecnia, v.28, n.1, p.195-204, 1999 b.

SIGNORETTI, R.D.; COELHO DA SILVA, J.F.; VALADARES FILHO, S.C. et al. Eficiência de utilização da energia metabolizável para ganho de peso e exigências de energia metabolizável, nutrientes digestíveis totais e proteína metabolizável de bezerros da raça holandesa. Revista Brasileira de Zootecnia, v.28, n.1, p.214-221, 1999c.

SMITH, N.E.; BALDWIN, R.L. Effects of breed, pregnancy and lactation on weight of organs and tissues in dairy cattle. Journal of Animal Science, v.57, n.9, p.1055-1060, 1974.

WEBSTER, A.J.F. Bioenergetics, bioengineering and growth. Animal Production, v.48, p.249-269, 1989.

Recebido em: 30/11/00

Aceito em: 22/08/02 